\title{
Changes in epidemiological indices following the introduction of WHO MDT into the Guyana leprosy control programme*
}

\author{
PATRICIA ROSE \\ The Coach House, Allendale House, Allendale Rd, Hexham \\ NE46 2DE, United Kingdom
}

Accepted for publication 20 January 1989

\begin{abstract}
Summary In December 1981 the multidrug regimen recommended by the WHO Study Group of October 1981, was introduced into the Guyana Hansen's Disease Programme. This paper examines the changes that occurred in epidemiological indices over the 6 years following the introduction of MDT and also evaluates changing work loads and staffing patterns.
\end{abstract}

\section{Introduction}

The present Guyana Leprosy Control Programme began in 1971, when dapsone monotherapy had been in use for nearly 20 years. Clofazimine and rif ampicin gradually became available and by the late 1970s multibacillary patients were receiving all 3 drugs together; rifampicin for a course of 3 weeks at the beginning of treatment and repeated annually until smear-negativity. All drugs were self-administered. Paucibacillary patients were treated for 2-10 years after inactivity and multibacillary patients, while remaining indefinitely on maintenance dapsone, were kept on the active register for 5 years after inactivity. Since MDT all patients have been moved onto a surveillance register on completing treatment and only those patients receiving treatment have been included in statistical returns. This paper describes the changes that occurred in epidemiological indices when the supervised treatment regimen recommended by WHO was introduced into a programme in which multibacillary patients were already receiving multiple drugs but were not receiving supervised treatment.

\section{Prevalence rates}

During the 6 years before MDT, 1975-81, the prevalence rate fell by steps from 0.9 to 0.6 per thousand-a fall of $33 \%$ or $5 \cdot 5 \%$ a year-whereas over the 6 years following MDT the rate of fall doubled to $67 \%$ or an average annual rate of fall of approximately $11 \%$. In the last 3 years, $1985-87$, the prevalence rate has been stable at $0 \cdot 2$ per thousand. The stepwise fall in prevalence before MDT is clearly shown in Figure 1 (the rise in 1982 is an artefact due to the fact that following MDT all patients on treatment, regardless of activity, are included in prevalence calculations whereas before MDT only clinically active patients were so included). Over the 3 years before multiple drugs were used the prevalence rate fell by $0 \cdot 1$ per thousand, in the next 3 years - when both multiple drugs and

* The above paper was presented at the XIII ILA Congress in The Hague, September 1988. 


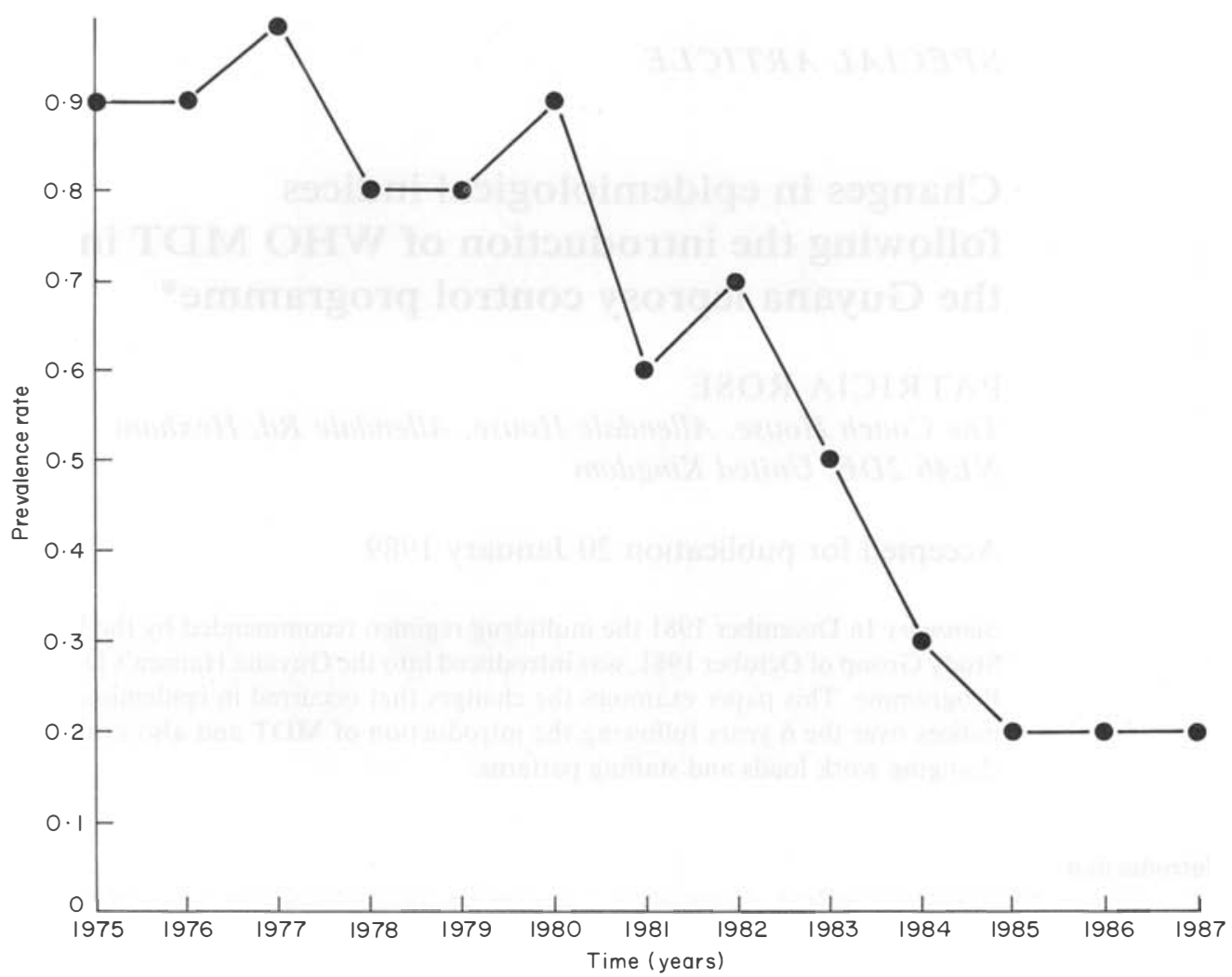

Figure 1. Prevalence rates per thousand population, 1975-87.

grant aid were available - prevalence fell by $0 \cdot 2$ per thousand and in thefirst 3 years of MDT the rate fell by $0 \cdot 3$ per thousand.

So, when introduced into a programme in which the prevalence rate was already falling, MDT produced an appreciable and sustained increase in the rate of decline of prevalence. Any further decline is likely to be slow as the use of MDT has altered the composition of the pool of patients on treatment from one almost equally divided between paucibacillary and multibacillary to one where about $70 \%$ of the patients at year-end are multibacillary.

\section{Incidence rates}

Incidence measures the number of new cases occurring in a defined population during a specific time, usually a year. This implies a state of perfection in which all new cases are identified as they occur but because this is difficult to achieve a case-detection rate may be calculated instead. Figure 2 gives the case-detection rates per 100,000 population for the period $1975-87$. The rate increased in the late 1970s, following programme expansion on receipt of external budgetary support, peaked at $14 / 100,000$ in 1982 and fell to a level of 7/100,000 in 1986 and 1987. However, before using these figures to judge the effect of MDT on incidence it is wise to ensure that the case-detection rate is 


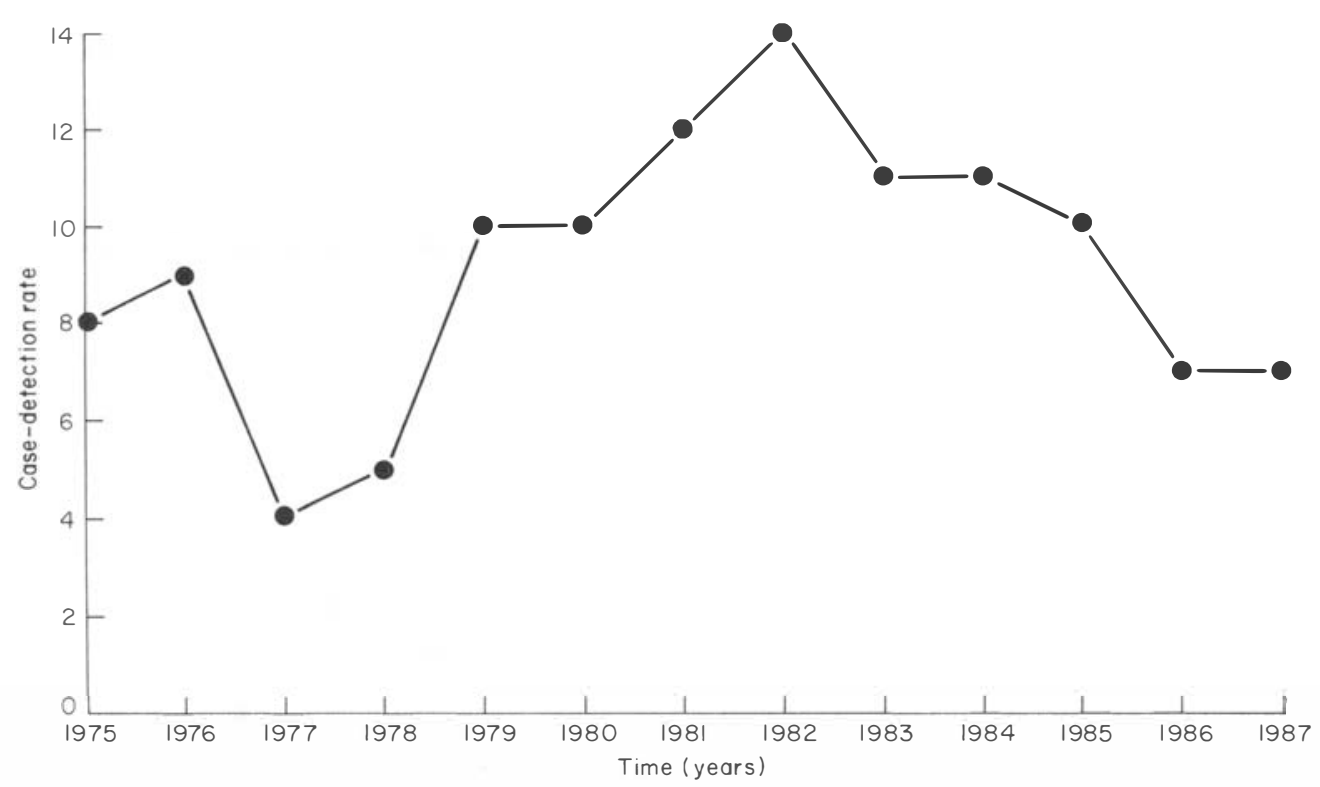

Figure 2. Case-detection rates per 100,000 population, 1975-87.

actually representative of incidence. There are three ways of gauging the validity of case-detection rates with regard to incidence.

\section{ASSESSMENT OF THE PROPORTION OF DISABLED NEW PATIENTS}

Firstly, the assessment of the proportion of disabled new patients is helpful. As deformities usually take a long time to develop patients should, ideally, be identified before they become disabled and a large number of disabled new patients indicates that many are suffering from long-standing disease. A study of the ages of new patients in Guyana between 1971 and 1986 has shown that disabled patients have been at least 8 years older, on diagnosis, than nondisabled patients and in 13 of the 16 years under review the age differential was at least 15 years. Ideally the proportion of disabled patients should tend towards zero as the case-detection rate approaches the incidence rate. Figure 3 shows that there was a gradual fall from a disability rate of just below $20 \%$ in 1975 to a rate of $1.3 \%$ in 1985. In 1986 and 1987 disability rates have been rather higher, at $11 \%$ and $9 \%$, respectivelypossibly resulting from a fall in the numbers of new patients and more aggressive case-finding.

PROPORTION OF MULTIBACILLARY PATIENTS AMONGS NEW PATIENTS

The second way of validating case-detection rates is to calculate the proportion of multibacillary patients amongst new patients. At the start of a programme this proportion will be high but should tend to fall to a baseline corresponding to the true proportion of new multibacillary patients. So, when this proportion stabilizes the detection rate can be assumed to be close to the incidence rate. In Guyana the proportion of multibacillary new patients fell from $36 \%$ in 1978 to $12 \%$ in 1983 and has since risen gradually to $22 \%$ in 1987 . 


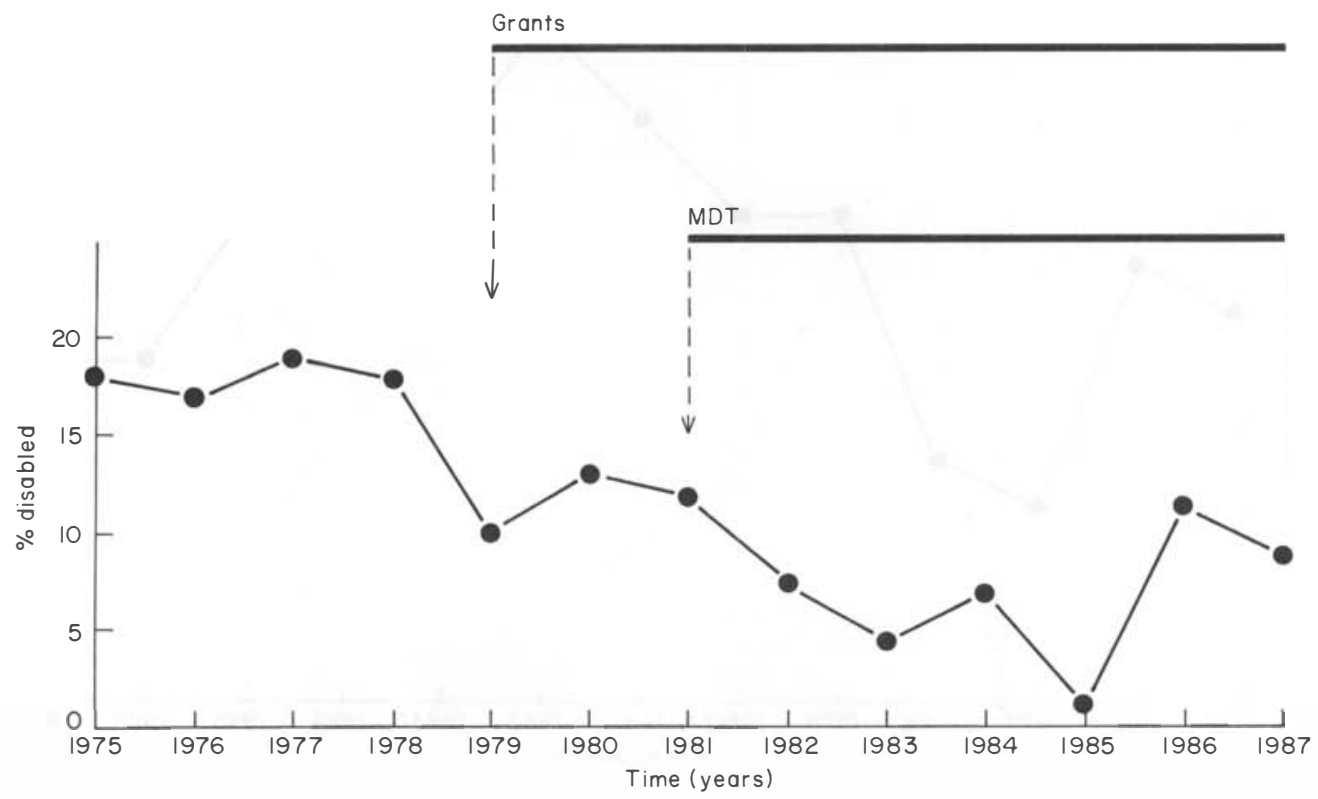

Figure 3. Percentage of new patients disabled (Grades I and II), 1975-87.

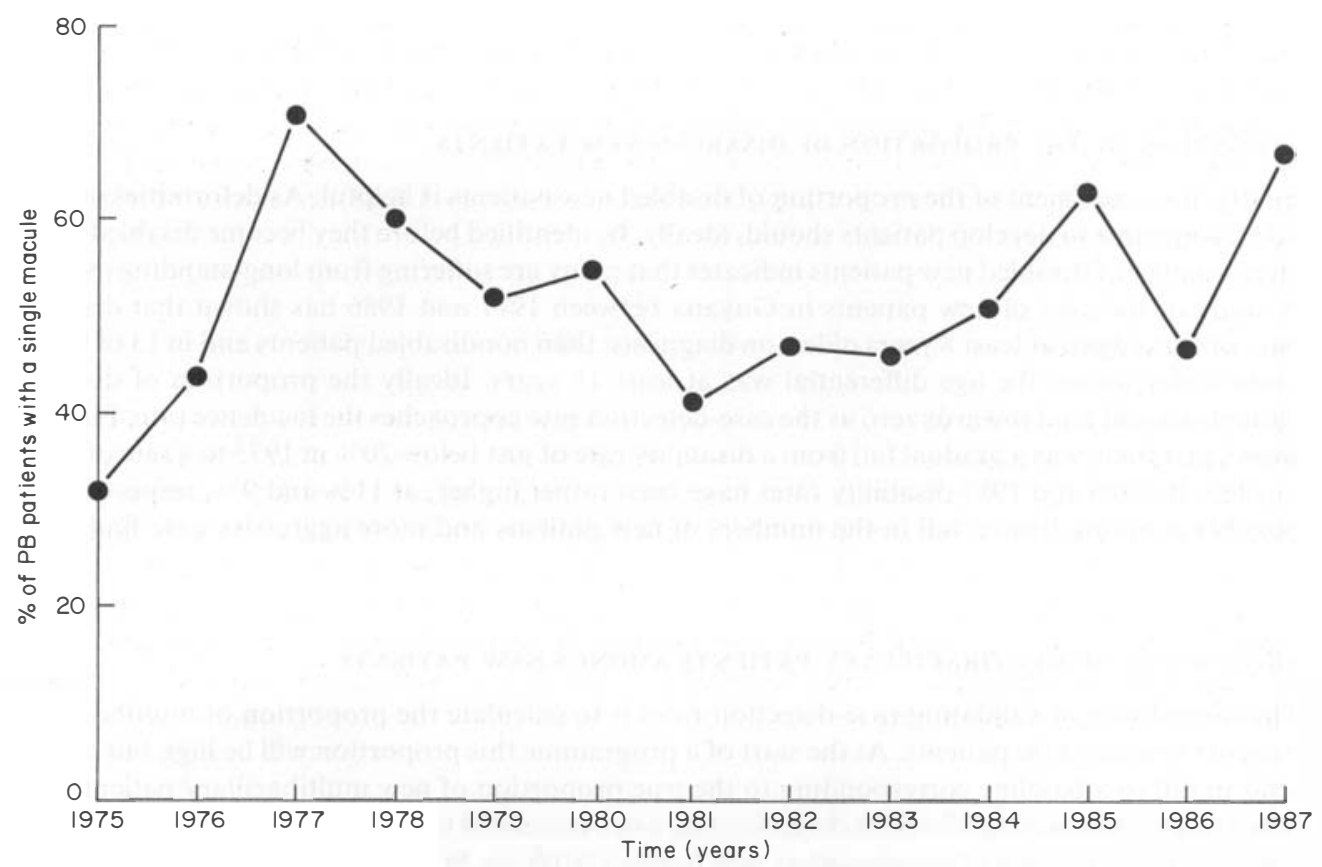

Figure 4. Percentage of paucibacillary patients with a single macule, 1975-87. 


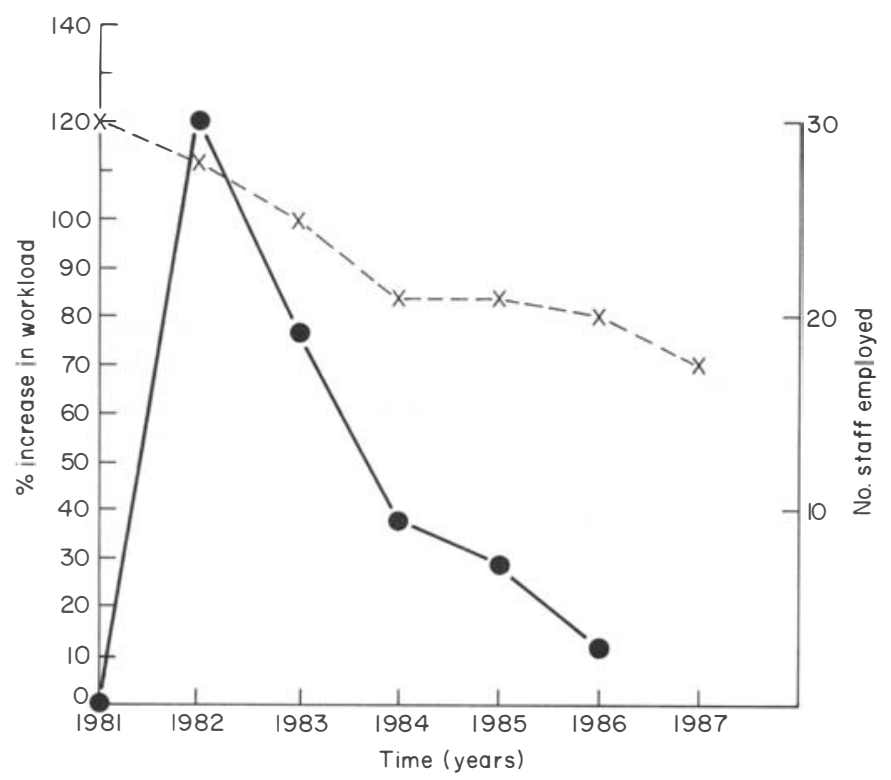

Figure 5 . increase in workload on the introduction of MDT; $\times--\times--\times$, staff numbers.

PROPORTION OF PAUCIBACILLARY PATIENTS PRESENTING WITH A SINGLE MACULE

Thirdly, the proportion of paucibacillary patients presenting with a single macule should increase as case-finding intensifies and Figure 4 shows that this proportion rose from $32 \%$ in 1975 to $72 \%$ in 1977 and then fluttered around the 50\% level with peaks of $63 \%$ in 1985 and $67 \%$ in 1987.

So, there are reasonable grounds, from all three methods of assessing validity, to accept the casedetection rates of Figure 2 as an indication of incidence rates. The fall in incidence from 1982 is very striking and although undoubtedly other factors are involved, this definite and sustained fall can be attributed in large part to the introduction of MDT.

\section{Increase in workload}

Changing from a programme where all drugs are self-administered and in which most patients are seen quarterly to one in which patients attend monthly for supervised drugs has resulted in a considerable increase in workload. One way of monitoring this increase is to compare clinic attendance figures. Figure 5 shows that domiciliary clinic attendances rose by $120 \%$ in 1982, taking 1981 as a baseline. This tremendous increase had fallen to $12 \%$ by 1986 . Where there is no possibility of obtaining additional staff members, constant improvement in working methods is needed to absorb this additional burden. Figure 5 also shows that there was a fall in the number of staff employed over this period, from 30 in 1982 to $17 \frac{1}{2}$ in 1987 - partly due to financial constraints and partly to improved working methods.

\section{Conclusion}

In conclusion there can be no doubt that the introduction of the WHO multiple drug regimen into 
the Guyana programme in December 1981 has had an advantageous effect on both prevalence and incidence rates. The tremendous increase in workload that was at first experienced had almost returned to pre-MDT levels by the end of 1986 and as the workload declined it was possible to reduce staffing levels without adversely effecting the standard of care given to patients.

\section{Acknowledgments}

This work was made possible by the generous support of ILEP members, especially American Leprosy Missions, the Netherlands Leprosy Relief Association and WHO/PAHO, to all of whom we are extremely grateful. I am indebted to Professor Lechat for the methods of validating incidence rates as set out in his monologue entitled 'Basic Epidemiological Indicators for Monitoring Leprosy Control'. 